\title{
'n Vergelyking van die resultate van vier rekenaarsoekmetodes vir taktiese produksiebeplanning
}

\author{
J.T. Meij \\ Departement van Bedryfsingenieurswese, Universiteit van Stellenbosch
}

\begin{abstract}
A comparison of the results of four computer search-models for production planning. Many production managers are faced with the problem of planning production, inventory and workforce under the constraint of limited resources to meet a seasonal demand. Considerable research has been done on this planning problem and various models have been proposed. The linear decision rule (LDR), especially as applied to the well-known Paint Shop, represents a milestone in the development of such models and serves as a standard against which the performances of many other models are measured. In this paper a comparison is made between the LDR results and that of three computer search models, SDR, CONMIN and SUMT for the Paint Shop. Two different cost structures are used for the Paint Shop - the original structure developed by Holt et al. (a quadratic approximation to the costs of the Shop) and a ficticious fourth-order cost structure published by Goodman. The results of this study indicate that in cases where the cost structure is non-linear, the computer search techniques can be of some help to the production planner.
\end{abstract}

S. Afr. J. Bus. Mgmt. 1982, 13: 142- 147

Verskeie alternatiewe optimeringsmetodes is aan die hand gedoen vir die bepaling van 'n optimale taktiese produksieplan vir die moderne vervaardigingsonderneming. Een van hierdie metodes staan bekend as LBR (Lineêre Besluitreel). In hierdie benadering maak die outeurs die aanname dat die kostestruktuur van 'n onderneming met kwadratiese kostefunksies benader kan word. Die tegniek word met groot sukses by 'n Verf-fabriek toegepas. In hierdie artikel word verslag gedoen oor die gebruik van drie rekenaarsoekmetodes (CONMIN, SUMT en SDR) vir die bepaling van die beste produksieplan vir die Verf-fabriek en 'n vergelyking van die resultate met dié van LBR word getref. 'n Fiktiewe vierde-orde kostestruktuur, soortgelyk aan dié van die Verf-fabriek, is deur Goodman saamgestel. Die rekenaarsoekmetodes word ook op hierdie kostestruktuur toegepas en vergelyk. Die resultate toon dat rekenaarsoekmetodes in die algemeen met sukses gebruik kan word vir hierdie soort probleem.

S.-Afr. Tydskr. Bednfsl. 1982, 13: $142-147$

Derde in 'n reeks van drie artikels

\section{Inleiding: die probleem}

Die moderne vervaardigingsonderneming is genoodsaak om die bronne tot sy beskikking vir vervaardiging maksimaal te benut. In taktiese produksiebeplanning, waarin die optimale benutting van die bronne nagestreef word, word op die mediumtermyn beplan vir produksiehoeveelhede, voorraadhoeveelhede en die arbeidsmag. Verskeie metodes is voorgestel vir die bepaling van die optimum werksmag, voorraadvlak en produksietempo vir die onderneming vir'n gekose beplanningshorison. By die optimering van koste speel die kostestruktuur van die onderneming ' $n$ besondere rol. As gevolg van die wiskundige beperking op van die voorgestelde wiskundige modelle kan net lineêre of kwadratiese benaderings gemaak word van die werklike kostestruktuur van die onderneming. Die optimering van 'n wiskundig vereenvoudigde kostestruktuur kan lei tot bestuursbesluite wat, gesien in die lig van die werklike komplekse kostestruktuur van die onderneming, nie optimaal is nie. Die soekmetodes wat in hierdie artikel bespreek word, oorbrug hierdie beperking deurdat dit volgens 'n spesifieke patroon in die komplekse meer-dimensionele werklike kostefunksieruimte na die optimum soek. Hierdie soektog is nie krities afhanklik van die wiskundige struktuur van die kostefunksie nie, en die kostemodel kan dus so kompleks wees soos wat die werklike situasie vereis.

\section{Tweedemags-kostemodel}

Die eerste kostemodel wat gebruik is, is dié vir 'n Verffabriek wat deur Holt, Modigliani, Muth en Simon' saamgestel is. Hulle het die werklike kostestruktuur van die Verffabriek met 'n stel lineêre en kwadratiese funksies benader. Hierdie funksies kan saamgestel word tot 'n kwadratiese doelwitfunksie met ' $n$ stel beperkingsfunksies.

Die kwadratiese doelwitfunksie vir die totale koste van die Verffabriek, wat gewone lone, aanstellingskoste, afdankingskoste, oortydkoste, ledigetydkoste en voorraaddrakoste insluit, is soos volg:

$$
\begin{aligned}
C_{N} & =\sum_{t=1}^{n}\left[340 W_{t} \quad \ldots \ldots \ldots .\right. \text { gewone lone } \\
& +64,3\left(W_{t}-W_{t-1}\right)^{2} \ldots \ldots \ldots . . \begin{array}{l}
\text { werksmagverande- } \\
\text { ringskoste }
\end{array}
\end{aligned}
$$$$
+0,20\left(P_{t}-5,67 W_{t}\right)^{2}+51,2 P_{t}-281,0 W_{t}
$$
oortyd/ledigetydkoste

Hoof van Departement van Bedryfsingenieurswese, Universiteit van Stellenbosch, Stellenbosch 7600 , Republiek van Suid-Afrika 
$\left.+0,0825(I,-320)^{\overline{2}}\right] \ldots \ldots \ldots$ voorraaddrakoste

Onderhewig aan die volgende materiaalbalansbeperkings:

$P_{t}+I_{t-1}-I_{t}=D_{t}$ vir alle $t$,

waar

$W_{t}=$ Werksmag (aantal arbeiders) in periode $t$,

$W_{t-1}^{t}=$ Werksmag (aantal arbeiders) in die vorige periode,

$P_{t}=$ Produksievlak (gelling verf) in periode $t$,

$I_{t}=$ Eindvoorraad in periode $t$,

$I_{t-1}=$ Eindvoorraad van die vorige periode en

$D_{t}=$ Vraag in periode $t$.

Die optimale produksieplan met betrekking tot arbeidsmag, produksiehoeveelheid en voorraadvlakke is bepaal met behulp van parsiële differensiaalrekening en die oplossing van 'n stel lineêre vergelykings. Vir die doeleindes van hierdie studie is die optimale oplossing van Holt et al. geneem as die werklike Verffabrief-kostestruktuur sodat rekenaarsoekmetodes hiermee en met mekaar vergelyk kan word. Aangesien die lineêre besluitreëls (LBR), wat sodoende ontwikkel is, wiskundigbewysbare optimale oplossings vir die bostaande kostestruktuur gee, is die optimale produksieplan vir die bepaalde beplanningshorison dus bekend. Twee beplanningshorisonne, naamlik 12 maande en 24 maande, is gebruik in die vergelykings.

\section{Die vierdemags-kostemodel}

Die tweede kostemodel wat gebruik is, is afkomstig uit 'n publikasie van Goodman ${ }^{2}$ waarin die Verffabriek se kwadratiese kostestruktuur fiktief uitgebrei is na 'n vierdeorde kostefunksie. Aangesien hierdie model baie meer sensitief is vir klein veranderinge in die totale produksieplan, is verwag dat dit groter verskille tussen die rekenaarsoekmetodes sal uitwys. Die doelwitfunksie is soos volg:

$$
\begin{aligned}
& C_{N}=\sum_{i=1}^{n} \quad\left[340 W_{t} \quad \ldots \ldots \ldots\right. \text { gewone lone } \\
& +64,3\left(W_{t}-W_{t-1}\right)^{4} \quad \ldots \ldots \ldots . . \text { werksmagverande- } \\
& \text { ringskoste } \\
& +0,2\left(P_{t}-6 W_{t}\right)^{4} \quad \ldots \ldots \ldots \text { oortyd } / \\
& \text { ledigetydkoste } \\
& +0,1\left(P_{t}-P_{t-1}\right)^{4} \quad \ldots \ldots \ldots \text { produksievlak ver- } \\
& \text { anderingskoste } \\
& \left.+0,1(I,-320)^{4}\right] \\
& \text { voorraaddrakoste, }
\end{aligned}
$$

onderhewig aan dieselfde materiaalbalansbeperkings as vir tweedemags-kostemodel wat reeds gegee is. Die simbole het ook dieselfde betekenis as vir tweedemags-kostemodel. 'n Vergelyking van die resultate van die verskillende soekmetodes word nou vir die bostaande hoër-orde kostestruktuur gedoen.

\section{Rokenaarsoekmetodes}

Die toepasbaarheid en prestasie van drie verskillende rekenaarsoekmetodes is getoets op bostaande twee kostemodelle vir beplanningshorisonne van 12 maande en 24 maande. Die drie soekmetodes wat gebruik is, is:

- Die 'Search Decision Rule' (SBR) ontwikkel deur
Taubert. ${ }^{3}$ Dit is spesifiek ontwikkel om te gebruik vir taktiese produksiebeplanningsprobleme en maak gebruik van die Hooke-Jeeves-patroonsoekmetode.

- Die 'Sequential Unconstrained Minimization Technique' (SUMT) van Fiacco en McMormick. ${ }^{4}$

- Die 'Constrained Minimization'-soekmetode (CONMIN) van Haarhoff, Buys en Von Molendorff.

Die drie rekenaarsoekmetodes soek almal, volgens 'n patroon eie aan elke soekmetode, in die $N$-dimensionele funksieruimte na 'n minimum doelwitfunksiewaarde. Die metodes verskil ook ten opsigte van die metodiek wat gevolg word om beperkingsfunksies in ag te neem.

Die Soek-Besluitreël (SBR) van Taubert gebruik die patroonsoektog, ontwikkel deur Hooke en Jeeves, ${ }^{6}$ as basis. Die soekmetode is gebaseer op die beginsel dat as ' $n$ beweging van een punt na' $n$ ander in ' $n$ n-dimensionele ruimte suksesvol was, die volgende beweging ook in daardie rigting gemaak moet word. Die soeksubroetine bestaan dan ook uit twee dele, naamlik 'n ondersoek-soektog wat die plaaslike eienskappe van die responsvlak rondom die basispunt evalueer, en 'n beweeglogika wat die inligting uit die ondersoek gebruik om die verskuiwing van die basispunt te administreer. Die resultate wat Taubert vir die tweedemagsmodel behaal het, word hierin gebruik.

Die SUMT-rekenaarsoekmetode vind die minimum van 'n meer-dimensionele, nie-lineêre, of lineêre doelwitfunksie onderhewig aan eweredigheids- sowel as ongelykheidsbeperkings. In die metode word die doelwitfunksie en beperkings gekombineer in ' $n$ nuwe onbeperkte doelwitfunksie wat dan deur 'n gepaste multi-dimensionele, onbeperkte minimeringstegniek ondersoek word. Die SUMT-rekenaarsoekmetode bied 'n keuse van vier minimeringsmetodes, naamlik:

- die algemene Newton-Raphson-metode,

- die metode van Newton en Raphson soos aangepas deur Fiacco en McCormick, ${ }^{4}$

- die steilste helling soektog en

- die Fletcher-Powell-metode soos aangepas deur McCormick. ${ }^{4}$

Die Fletcher-Powell-metode het deurgaans die beste presteer in toetslope. Alle SUMT-resultate wat hier gegee is, is met die metode verkry.

Die CONMIN-rekenaarsoekmetode omvorm ook die oorspronklike doelwitfunksie en die beperkings tot 'n nuwe onbeperkte doelwitfunksie. Die metode van Fletcher en Powell ${ }^{7}$ word ook gebruik om die nuwe onbeperkte doelwitfunksie te minimeer. Dié rekenaarsoekmetode verskil egter van die SUMT-rekenaarsoekmetode in die manier waarop die gemodifiseerde onbeperkte doelwitfunksie uit die oorspronklike doelwitfunksie en die beperkings saamgestel word.

\section{Resultate}

\section{Rekenaartyd en konvergensietempo}

Vergelykings is gemaak van die rekenaartyd en konvergensietempo van die SUMT- en CONMIN-soekmetodes. Die totale rekenaartyd op die UNIVAC 1110 van die Universiteit van Stellenbosch (insluitend die tyd vir die MAP-verwerker) vir die twee beplanningshorisonne (12 en 24 maande onderskeidelik) word in Tabel 1 gegee vir albei kostestrukture. Hieruit blyk dit dat die CONMINsoekmetode ongevoeliger is as die SUMT-soekmetode vir 
'n toename in die dimensies van die probleem vir die tweedemags-kostestruktuur. In die geval van die vierdemags-kostestruktuur vind die omgekeerde plaas, maar presteer CONMIN heelwat beter in ' $n$ korter tyd as SUMT wat betref die optimale koste. In Figuur 1 word 'n vergelyking getoon tussen die konvergesietempo van die twee soekmetodes. CONMIN konvergeer baie gou (binne minder as $40 \mathrm{~s}$ tot ongeveer $6 \%$ van die optimum af) terwyl SUMT 'n baie stadiger konvergensietempo toon.

Tabol 1 Rekenaartyd (insluitend MAP) vir CONMIN en SUMT

\begin{tabular}{crrrr}
\hline \multirow{2}{*}{$\begin{array}{c}\text { Aantal } \\
\text { dimensies }\end{array}$} & \multicolumn{2}{c}{ Tweedemagsmodel } & \multicolumn{2}{c}{ Vierdemagsmodel } \\
\cline { 2 - 5 } & SUMT (s) & CONMIN (s) & SUMT (s) & CONMIN (s) \\
\hline 24 & 66 & 72 & 177 & 142 \\
48 & 197 & 170 & 255 & 228 \\
$\begin{array}{l}\text { Minimum: (R) } \\
\text { koste }\end{array}$ & 718781 & 717265 & 13779182 & 13477848 \\
\hline
\end{tabular}

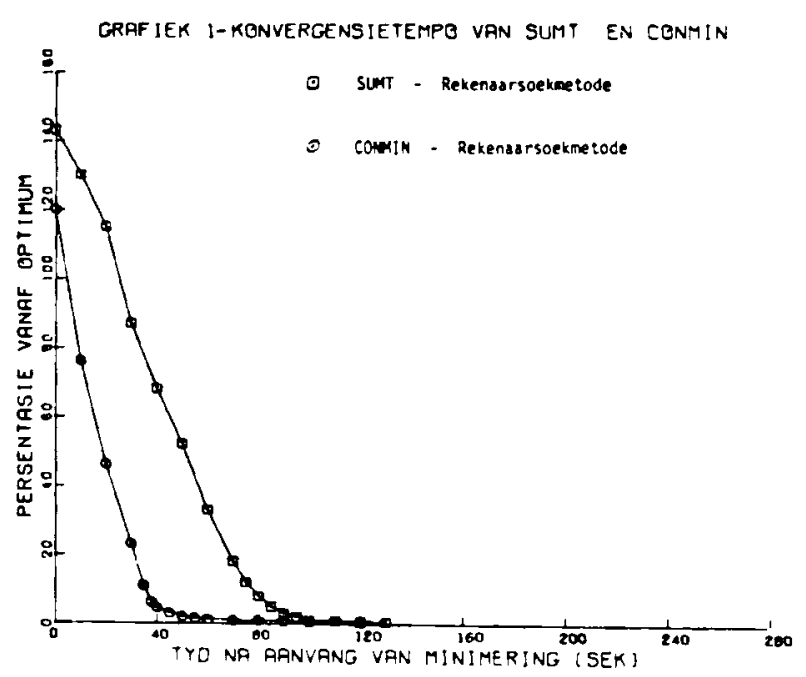

Figuar 1 Konvergensietempo van SUMT en CONMIN

\section{Resultate: Tweedemags-kostestruktuur}

Die resultate van die toepassing van die drie rekenaarsoekmetodes op die tweedemags-kostestruktuur van die Verffabriek in vergelyking met die optimum plan wat Holt et al. met behulp van die LBR verkry het, word vir 'n 20-maande beplanningshorison in Tabel 2 gegee. Die totale kosteresultate vir 20 maande is die volgende: (Sien Tabel 3.)

$$
\begin{array}{lll}
\text { LBR } & \text { R563 } 238 \\
\text { CONMIN } & : \text { R572 } 898(1,7 \% \text { hoër as LBR }) \\
\text { SUMT } & : \text { R573 } 197(1,8 \% \text { hoër as LBR }) \\
\text { SBR } & : \text { R574 } 130(1,9 \% \text { hoër as LBR })
\end{array}
$$

Die lineêre besluitreël-resultate is verkry met twee opeenvolgende beplanningshorisonne van 12 maande elk om sodoende produksie-, voorraad- en arbeidsmagplanne vir 24 maande te bereken. Die resultate van die soekmetodes is verkry met 'n 24-maande beplanningshorison met die eindvoorraad in die laaste periode onbeperk gelaat. Die

\begin{tabular}{|c|c|c|c|c|}
\hline \multicolumn{2}{|c|}{ Tegniek } & \multicolumn{3}{|c|}{ LBR } \\
\hline $\begin{array}{l}\text { Periode } \\
\text { (maand) }\end{array}$ & $\begin{array}{l}\text { Vraag } \\
\text { (gell) }\end{array}$ & $\begin{array}{c}\text { Werksmag } \\
\text { (man) }\end{array}$ & $\begin{array}{l}\text { Produksie } \\
\text { (gell) }\end{array}$ & $\begin{array}{l}\text { Voorraad } \\
\text { (gell) }\end{array}$ \\
\hline 1 & 430 & 78 & 468 & 301 \\
\hline 2 & 447 & 75 & 442 & 296 \\
\hline 3 & 440 & 72 & 416 & 272 \\
\hline 4 & 316 & 69 & 382 & 337 \\
\hline 5 & 397 & 67 & 377 & 317 \\
\hline 6 & 375 & 66 & 368 & 311 \\
\hline 7 & 292 & 65 & 360 & 379 \\
\hline 8 & 458 & 65 & 382 & 303 \\
\hline 9 & 400 & 66 & 377 & 280 \\
\hline 10 & 350 & 67 & 366 & 296 \\
\hline 11 & 284 & 69 & 365 & 377 \\
\hline 12 & 400 & 72 & 404 & 381 \\
\hline 13 & 483 & 75 & 447 & 345 \\
\hline 14 & 509 & 79 & 477 & 313 \\
\hline 15 & 500 & 83 & 495 & 307 \\
\hline 16 & 475 & 87 & $\$ 11$ & 343 \\
\hline 17 & 500 & 91 & $\$ 43$ & 386 \\
\hline 18 & 600 & 96 & 595 & 380 \\
\hline 19 & 700 & 100 & 641 & 321 \\
\hline 20 & 700 & 103 & 661 & 282 \\
\hline
\end{tabular}
vergelykings hierbo word vir die eerste 20 maande van hier-
Tabel 2 Produksie-, werksmag- en voorraadbeplan. nig vir die lineêre besluitreêl

die totale beplanningshorison gedoen om die effek van verskille in eindvoorraad uit te skakel. Die totale kosteresultate van al drie die soekmetodes toon dat dit vir alle praktiese doeleindes dieselfde resultaat lewer as die kwadratiese programmeringsbenadering van Holt et al. CONMIN gee die beste kosteresultaat (slegs 1,7\% vanaf die globale optimum), hoewel die verskille tussen die kosteresultate van die metodes weglaatbaar klein is. Die produksie-, werksmag- en voorraadplanne is so te sê identies soos wat Figure 2, 3 en 4 toon.

\section{Resultate: Vierdemags-kostestruktuur}

Daar is nie 'n metode beskikbaar om vir die vierdemagskostestruktuur ' $n$ wiskundigbewysbare optimale oplossing te verkry nie, derhalwe kan die drie soekmetodes slegs onderling vergelyk word wat betref die aard van die produksieplan en die minimum totale koste bereken. Hierdie vergelyking word hieronder gedoen. Die totale kosteresultate vir 20 maande is die volgende:

SBR : R7 668659

CONMIN : R7 796774 (1,7\% hoër as SBR)

SUMT : R8 123473 (5,9\% hoër as SBR)

Soos in die geval van die tweedemags-kostemodel is die produksie-, voorraad- en arbeidsmagplanne vir ' $n$ totale beplanningshorison van 24 maande met ' $n$ onbeperkte eindvoorraadvlak bereken. (Sien Tabel 4.) Hierdie kostestruktuur is besonder kostesensitief vir klein veranderings in die beplanningsparameters. Figure 5, 6 en 7 toon hoe min die onderskeie planne verskil en tog is daar bykans 'n 6\% kosteverskil tussen die SBR- en die SUMT-plan. Die SBR-toepassing, uit 'n vorige studie, lewer wel die laagste koste-resultaat, maar dit is onbekend wat die rekenaartyd is wat gebruik is - in 'n langer tyd sou CONMIN sowel as SUMT na verwagting ook 'n laer totale koste lewer. 
Tabel 3 Produksie-, werksmag- en voorraadbeplanning vir die tweedemag-kostestruktuur

\begin{tabular}{|c|c|c|c|c|c|c|c|c|c|c|}
\hline \multicolumn{2}{|c|}{ Tegniek } & \multicolumn{3}{|c|}{ SBR } & \multicolumn{3}{|c|}{ CONMIN } & \multicolumn{3}{|c|}{ SUMT } \\
\hline $\begin{array}{l}\text { Periode } \\
\text { (maand) }\end{array}$ & $\begin{array}{l}\text { Vraag } \\
\text { (gell) }\end{array}$ & $\begin{array}{c}\text { Werksmag } \\
\text { (man) }\end{array}$ & $\begin{array}{l}\text { Produksie } \\
\text { (gell) }\end{array}$ & $\begin{array}{l}\text { Voorraad } \\
\text { (gell) }\end{array}$ & $\begin{array}{c}\text { Werksmag } \\
\text { (man) }\end{array}$ & $\begin{array}{l}\text { Produksie } \\
\text { (gell) }\end{array}$ & $\begin{array}{c}\text { Voorraad } \\
\text { (gell) }\end{array}$ & $\begin{array}{c}\text { Werksmag } \\
\text { (man) }\end{array}$ & $\begin{array}{c}\text { Produksie } \\
\text { (gell) }\end{array}$ & $\begin{array}{l}\text { Voorraad } \\
\text { (gell) }\end{array}$ \\
\hline 1 & 430 & 78 & 472 & 305 & 78 & 467 & 300 & 78 & 466 & 298 \\
\hline 2 & 447 & 74 & 443 & 301 & 75 & 442 & 295 & 74 & 416 & 267 \\
\hline 3 & 440 & 71 & 418 & 279 & 72 & 415 & 270 & 72 & 431 & 259 \\
\hline 4 & 316 & 68 & 385 & 348 & 70 & 381 & 335 & 70 & 391 & 334 \\
\hline 5 & 397 & 66 & 376 & 327 & 68 & 377 & 315 & 68 & 378 & 315 \\
\hline 6 & 375 & 64 & 366 & 318 & 67 & 368 & 307 & 66 & 364 & 304 \\
\hline 7 & 292 & 63 & 360 & 386 & 66 & 359 & 375 & 66 & 363 & 375 \\
\hline 8 & 458 & 63 & 382 & 309 & 66 & 383 & 300 & 66 & 370 & 287 \\
\hline 9 & 400 & 64 & 379 & 288 & 67 & 378 & 278 & 67 & 380 & 267 \\
\hline 10 & 350 & 64 & 366 & 304 & 68 & 366 & 394 & 68 & 375 & 292 \\
\hline 11 & 284 & 67 & 359 & 379 & 70 & 366 & 376 & 70 & 365 & 373 \\
\hline 12 & 400 & 70 & 401 & 380 & 72 & 405 & 381 & 72 & 399 & 373 \\
\hline 13 & 483 & 74 & 447 & 344 & 76 & 449 & 346 & 76 & 455 & 344 \\
\hline 14 & 509 & 78 & 479 & 314 & 79 & 479 & 316 & 79 & 494 & 330 \\
\hline 15 & 500 & 81 & 498 & 312 & 83 & 497 & 314 & 83 & 498 & 328 \\
\hline 16 & 475 & 86 & 510 & 348 & 86 & 514 & 352 & 86 & 511 & 363 \\
\hline 17 & 500 & 90 & 547 & 394 & 89 & $\$ 46$ & 398 & 89 & 551 & 414 \\
\hline 18 & 600 & 94 & 592 & 387 & 93 & 596 & 394 & 93 & 617 & 431 \\
\hline 19 & 700 & 98 & 642 & 328 & 95 & 640 & 335 & 95 & 610 & 342 \\
\hline 20 & 700 & 101 & 659 & 287 & 96 & 653 & 287 & 96 & 637 & 279 \\
\hline
\end{tabular}

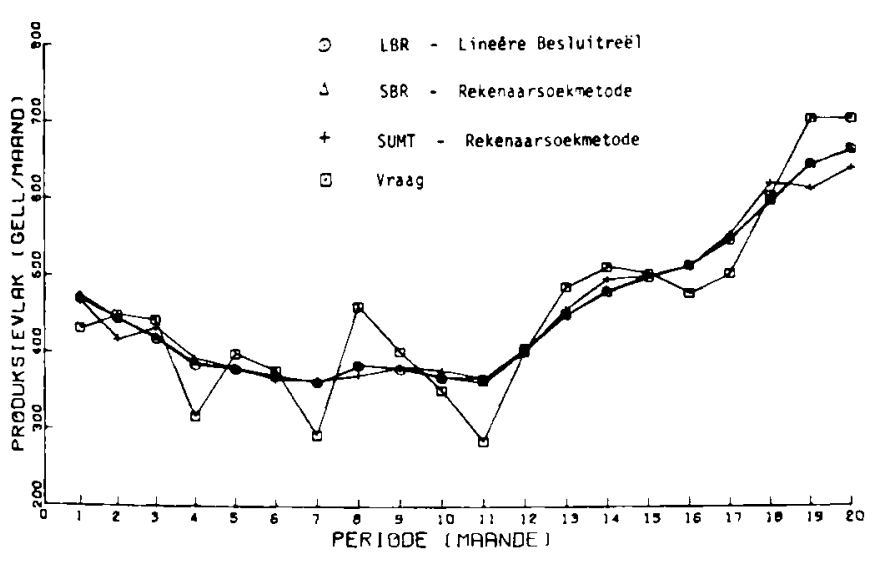

Figaur 2a Produksievlak teenoor periode

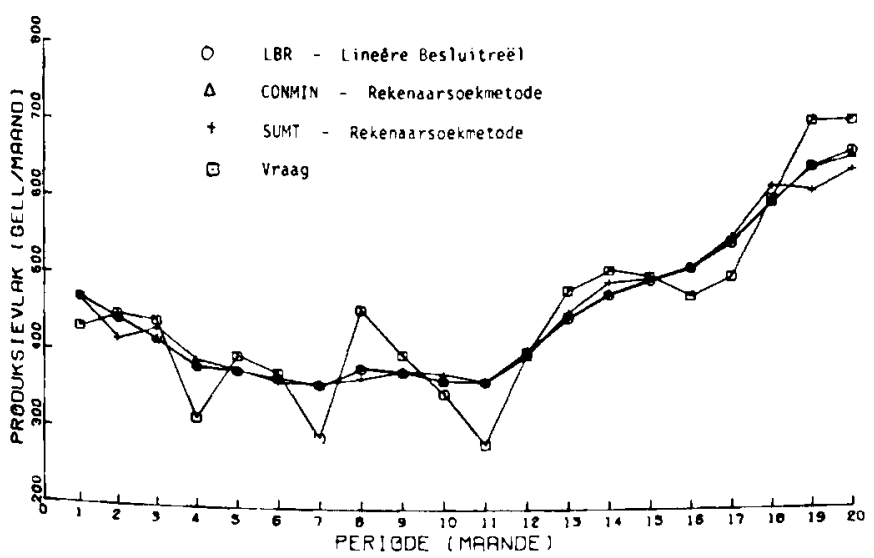

Figuar 2b Produksievlak teenoor periode

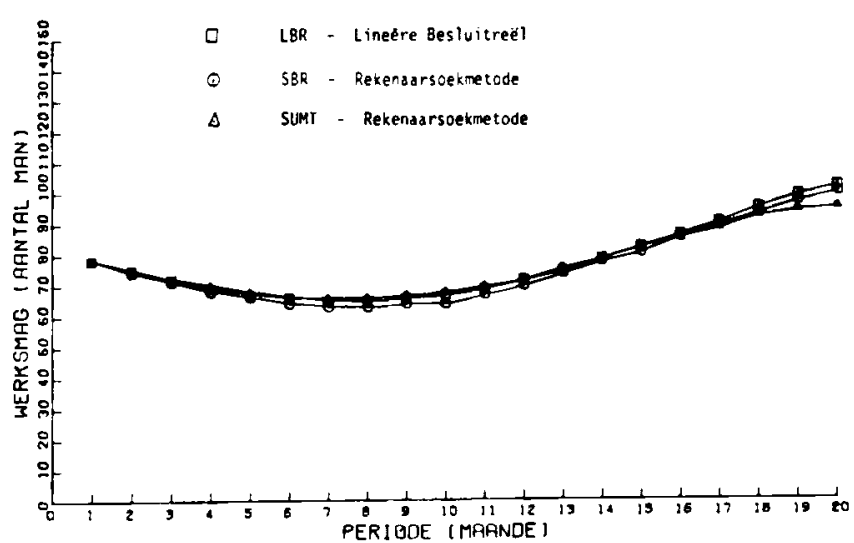

Figuur 3a Werksmag teenoor periode

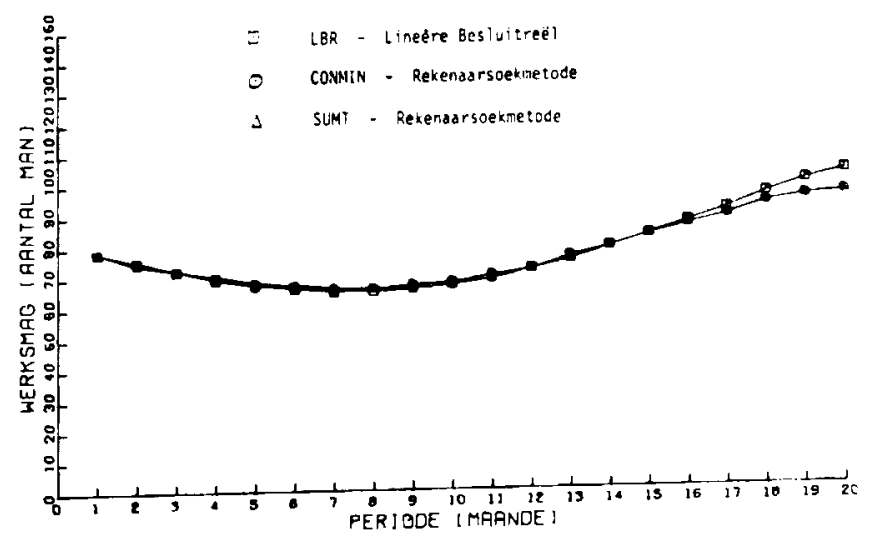




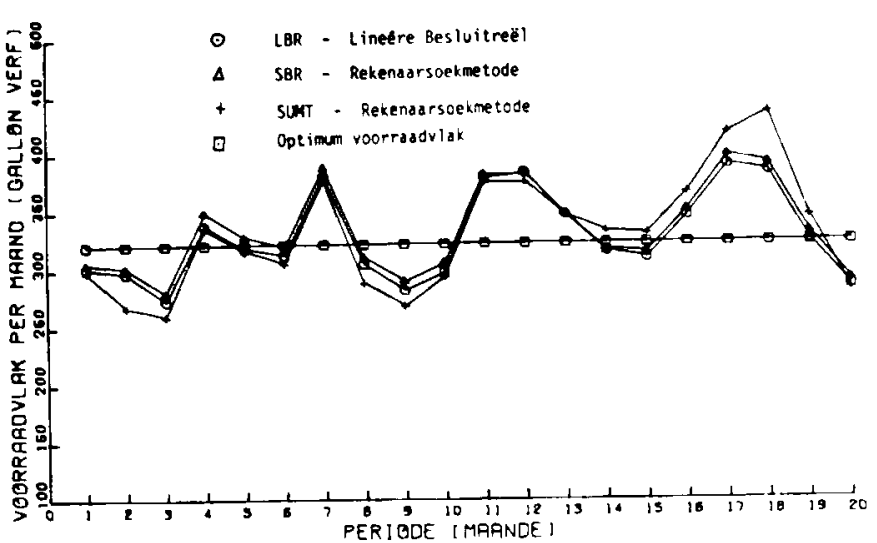

Flgaur an Voorraadvlak teenoor periode

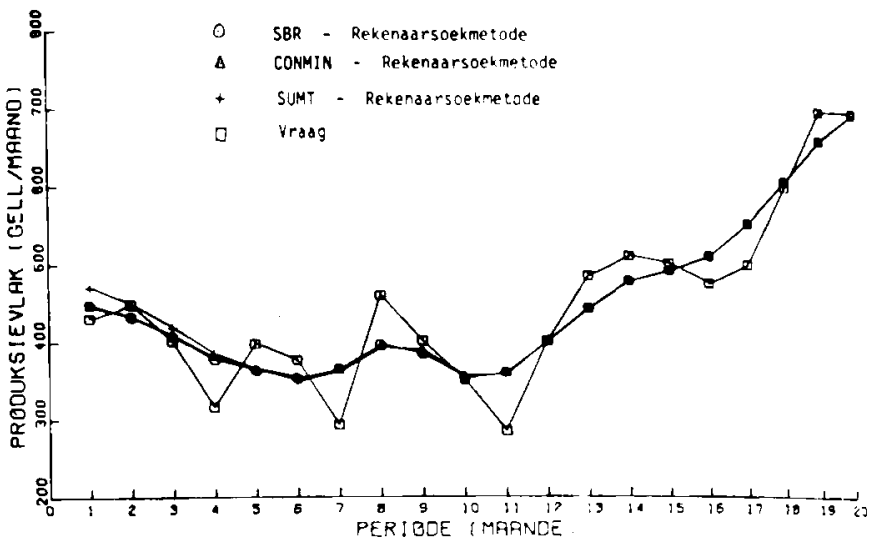

Figuur 5 Produksievlak teenoor periode

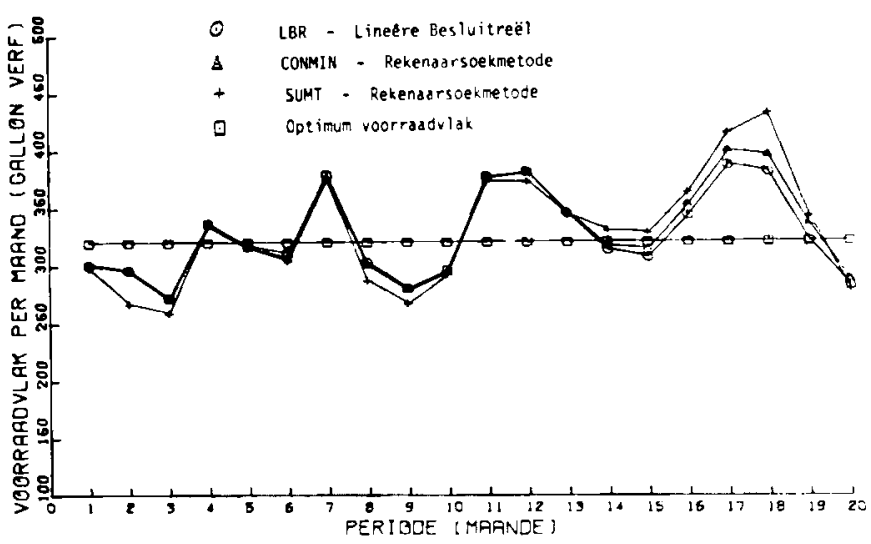

Figuur ab Voorraadvlak teenoor periode

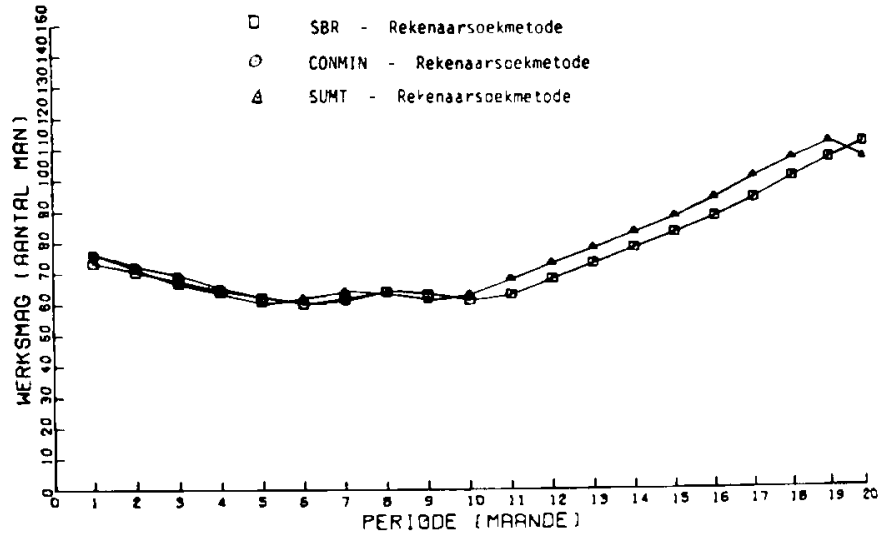

Figuur 6 Werksmag teenoor periode

Tabel 4 Produksie-, werksmag- en voorraadbeplanning vir die vierdemag-kostestruktuur

\begin{tabular}{|c|c|c|c|c|c|c|c|c|c|c|}
\hline \multicolumn{2}{|c|}{ Soektegniek } & \multicolumn{3}{|c|}{ SBR } & \multicolumn{3}{|c|}{ CONMIN } & \multicolumn{3}{|c|}{ SUMT } \\
\hline $\begin{array}{l}\text { Periode } \\
\text { (maand) }\end{array}$ & $\begin{array}{l}\text { Vraag } \\
\text { (gell) }\end{array}$ & $\begin{array}{c}\text { Werksmag } \\
\text { (man) }\end{array}$ & $\begin{array}{l}\text { Produksie } \\
\quad \text { (gell) }\end{array}$ & $\begin{array}{l}\text { Voorraad } \\
\text { (gell) }\end{array}$ & $\begin{array}{l}\text { Werksmag } \\
\text { (man) }\end{array}$ & $\begin{array}{l}\text { Produksie } \\
\text { (gell) }\end{array}$ & $\begin{array}{l}\text { Voorraad } \\
\text { (gell) }\end{array}$ & $\begin{array}{l}\text { Werksmag } \\
\text { (man) }\end{array}$ & $\begin{array}{l}\text { Produksie } \\
\text { (gell) }\end{array}$ & $\begin{array}{l}\text { Voorraad } \\
\text { (gell) }\end{array}$ \\
\hline 1 & 430 & 73 & 447 & 337 & 76 & 444 & 334 & 76 & 470 & 303 \\
\hline 2 & 447 & 70 & 431 & 321 & 72 & 431 & 318 & 71 & 448 & 304 \\
\hline 3 & 400 & 67 & 406 & 287 & 69 & 407 & 285 & 66 & 418 & 283 \\
\hline 4 & 316 & 64 & 376 & 347 & 65 & 379 & 348 & 63 & 384 & 351 \\
\hline 5 & 397 & 62 & 362 & 312 & 62 & 364 & 315 & 60 & 364 & 318 \\
\hline 6 & 375 & 60 & 352 & 289 & 60 & 353 & 293 & 62 & 349 & 291 \\
\hline 7 & 292 & 62 & 364 & 361 & 61 & 360 & 361 & 64 & 362 & 361 \\
\hline 8 & 458 & 64 & 395 & 298 & 64 & 391 & 294 & 63 & 394 & 298 \\
\hline 9 & 400 & 63 & 383 & 281 & 63 & 387 & 281 & 61 & 384 & 281 \\
\hline 10 & 350 & 61 & 353 & 284 & 61 & 355 & 285 & 63 & 353 & 285 \\
\hline 11 & 284 & 63 & 359 & 359 & 63 & 358 & 360 & 68 & 359 & 359 \\
\hline 12 & 400 & 68 & 399 & 358 & 68 & 399 & 358 & 73 & 399 & 358 \\
\hline 13 & 483 & 73 & 442 & 317 & 73 & 442 & 317 & 78 & 442 & 317 \\
\hline 14 & 509 & 78 & 477 & 285 & 78 & 477 & 285 & 83 & 477 & 285 \\
\hline 15 & 500 & 83 & 491 & 276 & 83 & 491 & 276 & 88 & 492 & 277 \\
\hline 16 & 475 & 88 & 510 & 311 & 88 & 510 & 311 & 94 & 510 & 311 \\
\hline 17 & 500 & 94 & 553 & 364 & 94 & 553 & 364 & 101 & 553 & 364 \\
\hline 18 & 600 & 101 & 608 & 372 & 101 & 608 & 372 & 107 & 607 & 371 \\
\hline 19 & 700 & 107 & 662 & 334 & 107 & 663 & 335 & 112 & 662 & 334 \\
\hline 20 & 700 & 112 & 698 & 332 & 112 & 698 & 332 & 107 & 698 & 332 \\
\hline
\end{tabular}




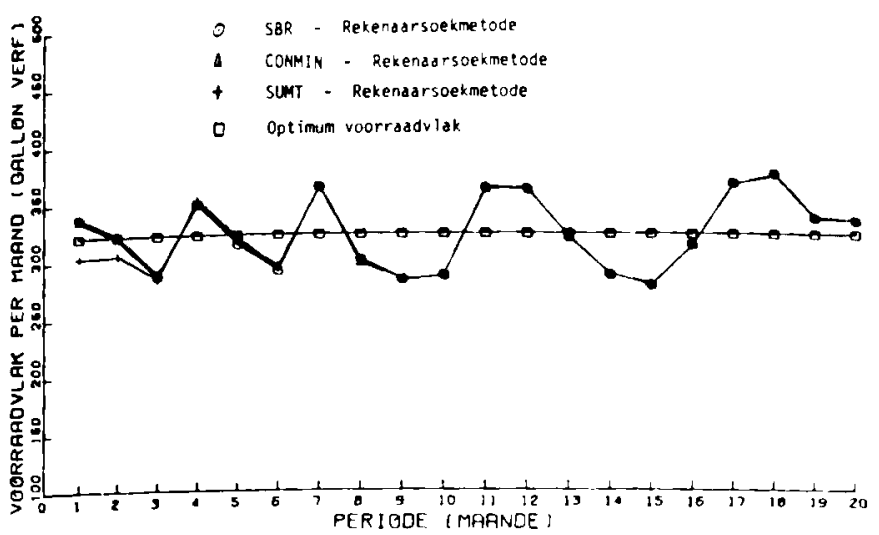

Figuur 7 Voorraadvlak teenoor periode

\section{Gevolgtrekking on aanbeveling}

Die doel van hierdie ondersoek was eerstens om vas te stel of rekenaarsoekmetodes geskik is as hulpmiddels vir die bepaling van goeie produksieplanne en, tweedens, hoe goed die beplanning is wat hiermee gedoen kan word. Uit hierdie studie blyk dit dat die rekenaarsoekmetodes met goeie gevolge gebruik kan word vir dié soort probleem. In die algemeen is gevind dat die soektog nie krities afhanklik is van die definiëring van aanvangswaardes nie. Die produksiebeplanner behoort in elk geval 'n goeie aanvangsoplossing te kan bepaal. Die verwagting is dat die rekenaartyd drasties sal toeneem met ' $n$ verhoging in die aantal veranderlikes (bv. 'n multi-produk geval), wat dus 'n besondere beperking sal plaas op die gebruik van die soort benadering vir produksiebeplanning - hierdie aspek verg egter nog verdere ondersoek.

\section{Summary}

Many production managers are faced with the problem of planning production, inventory and work force under the constraint of limited resources to meet a seasonal demand. Considerable research has been done on this planning problem and various models have been proposed. The linear decision rule (LDR), especially as applied to the wellknown Paint Shop, represents a milestone in the development of such models and serves as a standard against which the performances of many other models are measured. In this paper a comparison is made between the LDR results and that of three computer search-models, SDR, CONMIN and SUMT for the Paint Shop. Two different cost structures are used for the Paint Shop - the original structure developed by Holt et al. (a quadratic approximation to the costs of the Shop) and a ficticious fourth-order cost structure published by Goodman.

In the case of the quadratic cost-structure, the results indicated very small differences between the optimum values obtained with all three search-models. In comparison with the proven optimal value of LDR the values for CONMIN are 1,7\%, SUMT, 1,8\% and SDR, 1,9\% higher. For all practical purposes we can state that the optimal value is duplicated by all the search-models.

The fourth-order cost structure is very sensitive to small changes in the planning parameters so that a small change in for instance production quantity can result in a large change in the total cost. In this case the results of the models is compared to the SDR-model because we have no proven optimal value and the SDR-cost was the best. The CONMIN value is $1,7 \%$ and the SUMT value $5,9 \%$ higher than that of SDR.

The purpose of this investigation was to gain some experience in the use of computer search-methods for the calculation of aggregate production plans and to compare some of the best known search-methods available. It was found in general that this method can best be used in cases where cost-structures are highly non-linear and where other optimization methods like linear programming cannot be used. The time taken for the search was not critically dependent on the initial solution provided. One can also expect that the computer time for a search will drastically increase with an increase in parameters (e.g. in a multiproduct case).

\section{Verwysings}

1. Holt, H.C., Modigliani, F. \& Simon, H.A. A Linear Decision Rule for production and employment scheduling. Manage. Sci. Vol.2, Nr.1, Okt. 1955, pp.1-30.

2. Goodman, D.A. A new approach to scheduling aggregate production and work force. A.I.I.E. Transactions, Vol.5, Nr. 2, Junie 1973, pp.135-141.

3. Taubert, W.H. A Search Decision Rule for the aggregate scheduling problem. Manage. Sci., Vol.14, Nr.6, Feb. 1968. pp.B343 - B359.

4. Fiacco, A.V. \& McCormick, G.P. The Sequental Unconstrained Minimization Technique for non-linear programming, a primaldual method. Manage. Sci., Vol.10, Nr. 2, Jan. 1964, pp. $360-366$.

5. Haarhoff, P.C. Buys, J.D. \& Von Molendorff, H. CONMIN: a computer programme for the minimization of a non-linear function subject to non-linear constraints. PEL 190, Atoomkragraad, Pretoria, soos aangehaal in Kuester, J.C. \& Mize, J.H., Optimization Techniques with Fortran, McGraw-Hill Book Company, Hersiene uitgawe, 1973, p.472.

6. Hooke, R. \& Jeeves, T.A. A Direct Search solution of numerical and statistical problems. J. Assoc. Comp. Mach., April 1961.

7. Soos beskryf in Kuester, J.L. \& Mize, J.H. Optimization Techniques with Fortran. McGraw-Hill Book Company, Hersiene uitgawe, 1973, pp.355-366. 